\title{
Escravidão Como Identidade: os Mamelucos Turcos no Egito Medieval
}

\author{
Slavery as Identity: the Turkish Mamluks in the Medieval Egypt
}

\section{Annie Venson Bogoni ${ }^{1}$}

\begin{abstract}
${ }^{1}$ Mestranda em História na Universidade Federal do Paraná (UFPR) sob orientação da Prof. Dra. Marcella Lopes Guimarães. Artigo produzido durante o projeto de pesquisa Legitimidade e Permanência do Governo Mameluco no Egito Entre 1250 e 1309. Contato: anniebogoni@gmail.com
\end{abstract}

Recebido em 04 de maio de 2020; Aceito em 13 de julho de 2020

\section{Resumo}

O presente artigo trata da questão da escravidão no Islã e como os mamelucos fizeram desta condição uma exclusividade da elite local e da posição de sultão. Identificamos também características como o uso da língua turca, a lealdade pessoal dos exércitos ao seu senhor e a imagem de guerreiros como pilares da identidade mameluca, a partir do imaginário muçulmano.

Palavras-chave: Escravidão militar; Egito; Islã; Mamelucos; Identidade.

\section{Abstract}

This article approaches the matter of slavery in Islam and how mamluks made this condition an exclusivity of the local elite and of the position of sultan. It was also identified characteristics such as the use of Turkish, the personal loyalty of the armies to their master, and the image of warriors as pillars of the mamluk identity, from the Muslim imagery.

Keywords: Military slavery; Egypt; Islam; Mamluks: Identity.

\section{A Escravidão no Islã}

Por muito tempo, e em muitos territórios, a escravidão foi parte da economia, da sociedade e da política. Ela perpassa o tempo e as fronteiras se pautando em uma definição: a posse de um ser humano por outro. Apesar de parecer específica e clara, esta definição ainda permite espaço para as variações que pertencem a cada contexto: a escravidão por dívidas da Grécia antiga se diferencia, e muito, da escravidão do século XVIII nas colônias portuguesas e espanhóis. A própria concepção de posse se liga 
diretamente à legislação local, muitas vezes relacionada também à moral religiosa regional.

No caso do Império Islâmico, o escravo podia exercer diversas funções, desde a doméstica até a militar, podendo trabalhar com certa autonomia ou sendo considerado como parte da família que o possuía. Poderia ser escravizado aquele que não fosse muçulmano, muitas vezes capturado em guerras, mas essa regra não era sempre seguida. Neste artigo, focaremos na escravidão militar, na aquisição de escravos que serviam como soldados e guerreiros em guerras. Estes exércitos serviam figuras politicamente importantes, muitas vezes possibilitando que os soldados comprados ascendessem a cargos militares mais altos. Um grupo conseguiu não apenas a ascensão como a tomada do poder local: os mamelucos turcos.

A compra de turcos capturados era comum no Oriente. A proximidade das tribos nômades turcas e o fato de não serem muçulmanos eram condições importantes para a contínua escravização destas populações. Outro fator era a estratégia militar dos turcos, a arquearia montada. Ela possibilitou a vitória em batalhas contra os guerreiros francos das Cruzadas. Os turcos constituíam grande parte do exército de Saladino e aumentaram em quantidade ao longo da dinastia Aiúbida. Por volta do século $\mathrm{XI}$, estes soldados escravos eram conhecidos (e se identificavam) como mamelucos.

É neste período que percebemos a extensão da diferença de status entre a escravidão militar e outras funções escravas. Os mamelucos que ascendiam os cargos militares podiam servir diretamente ao sultão como um emir ou um conselheiro pessoal. Conforme os sultões Aiúbidas se circundavam de mamelucos pessoais, uma elite de origem escrava e turca se formava, até que no século XIII este mesmo grupo tomou também a posição de sultão do Egito, criando um sultanato.

Portanto, este artigo se limita aos escravos turcos, que constituíam a maioria dos exércitos particulares dos governantes ou indivíduos poderosos do Sultanato Mameluco (1250-1517). Visamos entender qual era o papel da escravidão em sua identidade e na 
sua atuação na sociedade muçulmana como grupo, principalmente nos séculos XIII e XIV. Para isto, partimos de dois historiadores que escreveram sobre seu reinado, Ibn Khaldun (1332-1406) e Al-Maqrizi (1364-1442).

\section{A Regulamentação da Escravidão Mameluca}

Para melhor compreender o perfil e a trajetória mameluca, é necessário o aprofundamento no conceito de escravidão militar. A escravidão militar em larga escala se concretiza com o califa abássida Abū Ișhāq al-Mu'tașim em Bagdá no século IX, substituindo os soldados árabes que promoveram a expansão islâmica por escravos turcos particulares (AMITAI, 2006, 44). A nova força militar auxiliou na segurança e na política interna, além do combate externo contra bizantinos, servindo ao califa pessoalmente.

Esta prática continua com diversas outras dinastias. Até finais do século XII, os Fatímidas se circundavam de exércitos constituídos por berberes, negros do Sudão e turcos. A utilização de escravos militares, com laços de lealdade mais pessoais ao governante continua no Egito com os Aiúbidas, porém com a compra específica de jovens turcos. Como veremos, os próprios sultões mamelucos também possuíam suas tropas pessoais de escravos militares durante seu governo. Portanto, no século XIII percebemos a escravidão militar como uma instituição concretizada e, no caso egípcio, auto-perpetuante. A elite egípcia era constituída exclusivamente por aqueles que tivessem passado pela escravidão, ascendido socialmente e adquirido sua emancipação.

O termo utilizado para nomear o sultanato, "mameluco" (mam/ūk, singular; mamālīk, plural) se torna comum apenas a partir do século XI. Ele significa "controlado" ou "possuído" (no sentido de ser posse de alguém), mas muitas vezes se refere apenas a escravos militares brancos (AMITAI, 2007, 6), denominação que será utilizada tanto para os governantes turcos quanto para os circassianos. Outro termo comum é "turco", usado por Ibn Khaldun em grande parte de sua obra para se referir à elite egípcia. 
Esta forma de escravidão não se limitou ao Oriente Médio. Chouki El Hamel aponta características comuns encontradas ao longo de toda a bacia mediterrânea sob o Islã, porém focando nos escravos negros do Marrocos. O autor afirma que o Islã considerava a liberdade como condição natural da humanidade e destaca as três instâncias em que a escravidão era permitida: o nascimento de pais escravos, a captura durante a guerra, desde que o cativo não já fosse muçulmano, e, por último, a aquisição através da compra.

O Islã também regulava o tratamento destes indivíduos. Apesar de não possuírem poder legal ou acesso a cerimônias religiosas, os escravos podiam usufruir das responsabilidades atribuídas ao seu senhor. $O$ autor aponta que os senhores deviam "disponibilizar os meios para prover as necessidades vitais, tais como prover o escravo de atenção médica adequada, sustentá-lo quando idoso, evitar o sobretrabalho do escravo e eventualmente libertá-lo." (HAMEL, 2004, 16-17)

A emancipação era incentivada pelo Alcorão, considerada uma boa ação feita pelos senhores. No primeiro volume da obra "Histoire des Sultans Mamelouks de l'Égypte", Al-Maqrizi narra que em 1256 houve um grande incêndio seguido de terremotos em Medina. Além de suplicarem a Deus e implorarem por misericórdia, a população da cidade teria emancipado seus escravos e feito doações: "Les habitants de Médine allèrent se réfugier auprès du tombeau de l'apôtre de Dieu, lui adressèrent leurs supplications, et implorèrent la miséricorde de Dieu. Ils s'empressèrent d'affranchir leurs esclaves, et de distribuer d'abondantes aumônes." 32 (AL-MAQRIZI, 1837, 62) Percebemos neste trecho que a libertação de um cativo se compara a um ato de bondade ou de misericórdia, de uma forma que poderia agradar a Deus, portanto uma ação valorizada.

\footnotetext{
32 "Os habitantes de Medina foram para o túmulo do apóstolo de Deus, rogaram-lhe e imploraram a misericórdia de Deus. E depressa libertaram os seus escravos, e distribuíram abundantes esmolas." Todas as traduções são de nossa autoria.
} 
NEARCD: Revista Eletrônica de Antiguidade 2020, Volume XII, Número I - ISSN 19882-8713

Núcleo de Estudas da Antiguidade -NEA

Universidade do Estada do Rio de Janeiro

ISSN 1982-8713

Se no momento da escravização o indivíduo não fosse muçulmano, ele poderia ser mantido nesta condição mesmo após sua adesão à religião. A conversão de um escravo para o Islã não o tornava livre de imediato, dependendo apenas da emancipação concedida por quem o possuía. Lembramos que estas são regras gerais e que poderiam ser quebradas em casos específicos. Um exemplo é a captura e escravização de muçulmanos na região do atual Marrocos pelo sultão 'Alawi Sultan Mawlay Isma'il (1672-1727), para a formação de um exército apenas de escravos negros (HAMEL, 2004, 31). A emancipação era oficializada por meio de um documento escrito pelo senhor atestando a liberdade do escravo após sua morte ou ainda em vida. Em certos casos, os escravos poderiam herdar os bens materiais dos senhores após o falecimento destes.

O grupo abordado neste artigo, restrito aos mamelucos militares que estavam diretamente envolvidos com o governo, passavam por um tratamento específico. Devido ao seu status social mais alto em relação aos escravos que executavam atividades domésticas, eles usufruíam de treinamento militar e educacional. Os mamelucos eram ensinados a ler e escrever a língua árabe, assim como a aderir, e posteriormente se converter, à religião islâmica. De acordo com Reuven Amitai, os soldados recebiam uma certificação formal de liberdade durante uma cerimônia para este fim, atestando o fim de seu treinamento:

Em terceiro lugar, eu posso notar que no sultanato mameluco, pelo menos, os jovens mamelucos eram oficialmente alforriados no momento que completavam seu treinamento antes que eles fossem colocados nos ranques do exército regular. Isto era efetivamente realizado em uma cerimônia pública que combinava graduação e alforria, e os mamelucos recebiam um certificado para este efeito ${ }^{33}$ (AMITAI, 2007, 10).

\footnotetext{
33 "Thirdly, I might note that in the Mamluk Sultanate, at least, the young mamluks were officially manumitted at the time of the completion of their training before they were placed into the ranks of the regular army. This was actually performed in a public ceremony, which combined graduation with manumission, and the Mamluk received a certificate to this effect".
} 
NEARCD: Revista Eletrônica de Antiguidade 2020, Volume XII, Número I - ISSN 19882-8713

Núcleo de Estudas da Antiguidade -NEA

Universidade do Estada do Rio de Janeiro

ISSN 1982-8713

Percebe-se que a conversão e a emancipação destes escravos não eram apenas valorizadas de acordo com as recomendações religiosas, mas que foram transformadas em um processo sistemático. Isto demonstra uma normatização da liberdade concedida aos mamelucos que possibilitava o ingresso à elite egípcia e a cargos altos. Porém, devido às rivalidades internas e à acirrada competição por poder, muitos destes indivíduos se mantinham na condição de soldados rasos. Além disso, para aqueles que visavam a posição de sultão, a emancipação era crucial para adquirir o direito. Amitai afirma que Baybars apenas ocupou o trono de sultão após o sheik 'Izz al-Din Ibn 'Abd alSalam comprovar sua liberdade (AMITAI, 2007, 10).

A partir disto, também notamos a importância e uma possível forma de entender a inserção do escravo dentro desta sociedade. Os escravos eram parte da sociedade muçulmana, interagindo diretamente com a cultura e a religião do ambiente à sua volta. Porém, alguns autores defendem que no caso dos escravos militares, especialmente os turcos, a alienação destes em relação à população local era um dos fatores de interesse de seus senhores (AMITAI, 2006, 45-46). Este afastamento da sociedade favorecia uma maior aproximação do senhor, fortalecendo a lealdade pessoal destes soldados.

Em muitos casos, a possibilidade de ascensão social e de aquisição de cargos importantes era promissora e acessível a estes cativos. Se o senhor que os possuísse estivesse em uma posição política importante e de poder, era comum a nomeação de seus escravos como conselheiros ou que exerciam funções próximas de si. Albert Hourani afirma a importância desta corte de escravos, especialmente para governantes que visavam o mantimento de uma dinastia:

O primeiro objetivo de uma dinastia era manter-se no poder, e o governante portanto vivia meio apartado da população da cidade, cercado por uma corte em grande parte de origem militar ou estrangeira: sua família e harém, seus mamelucos pessoais - africanos negros ou cristãos convertidos do Magreb, turcos, curdos ou circassianos mais a leste - e altos funcionários do palácio, oriundos em grande parte desses grupos mamelucos. (HOURANI, 2006, 179180) 
Portanto, o autor destaca que a posse de escravos era vista como a posse de uma rede de apoio, político e militar, de caráter pessoal. Este círculo de indivíduos leais auxiliaria na perpetuação do reinado do senhor e, possivelmente, de seu filho, garantindo poder à dinastia. Observa-se que diversas dinastias utilizaram desse sistema, inclusive o próprio sultanato Mameluco, apontando seus escravos mais próximos para funções relacionadas aos afazeres reais. A corte (e por extensão, a elite), então, era constituída por indivíduos de origens geográficas e religiosas variadas, mas mantidos dentro de um mesmo grupo, definido pelo seu serviço a um senhor.

Isto é claramente percebido nos exércitos reunidos pelo governante, e pelos emires no caso mameluco, visto que eram grandes contingentes de pessoas cuja lealdade deveria se direcionar exclusivamente ao seu dono. Esta exclusividade em relação à lealdade somada à marginalização do escravo acabava por formar, na visão de um observador externo, uma espécie de solidariedade. Sob os mamelucos, os exércitos poderiam se identificar como um grupo identitário próprio que se relacionava diretamente à figura do dono destes escravos.

\footnotetext{
Também sob os mamelucos, o exército era de composição mista: o núcleo consistia de um corpo de mamelucos reais recrutados pelo governante ou deixados por seus antecessores e treinados nas escolas do palácio, mas os altos oficiais militares tinham, cada qual, um corpo de servidores militares próprio, treinados em sua casa. A solidariedade de um grupo criado na mesma casa podia durar uma vida inteira ou mais. (HOURANI, 2006, 180)
}

Em sua obra, Al-Maqrizi se refere a diversos exércitos a partir do nome de seu senhor, apresentando claramente a solidariedade apontada por Hourani. Um exemplo seria a tropa de mamelucos de Moëzz, que foi sultão a partir de 1250 até 1257: após a morte do governante pelas mãos de Shajar al-Durr, sua esposa, o grupo busca vingança por seu mestre. Ao apontar os opositores, que apoiaram al-Durr no assassinato, o autor os descreve como "mamelucos-sâlehis", pois estes seriam os escravos do Aiúbida AlSâleh. 
Além deste, outros grupos isolados que por razões diversas estejam se deslocando sem a presença de seu senhor, seguem esta mesma forma de denominação. Dois deles, os "Azizis" e os "Nâseris" (pertencentes a Melik-Aziz e Melik-Nâser, respectivamente) aparecem juntos na fonte por serem responsáveis pelo levante em Alepo contra Melik-Said-Ala-eddin (AL-MAQRIZI, 1837, 121). Al-Maqrizi, portanto, utiliza a posse destes indivíduos como definidora de sua identificação, sejam estes libertos ou ainda escravos. É importante destacar, também, como os dois conjuntos de militares citados interagem, criando um segundo laço de solidariedade a partir de um interesse comum imediato, se opor a uma figura local importante. A ausência de um senhor não significava o desmantelamento da unidade de soldados, mas uma oportunidade de agirem em conjunto de acordo com seus interesses próprios. Esta atuação independente se apresenta ao longo de toda a duração do sultanato, tanto interna como externamente.

Vários destes grupos tinham entre si chefes militares com poder o suficiente para guiá-los, adquirindo sua posição por meio da ascensão social que abordamos anteriormente. Para que um mameluco pudesse atingir a função de emir ou de sultão ele teria que ascender os cargos militares e superar as competições internas por poder. A importância desta trajetória é destacada por Al-Maqrizi nas introduções sobre os sultões Moëzz e Baybars. Sobre o primeiro, ele afirma: "Il monta successivement en grades, prit rang parmi les émirs Sâlehis, et obtint le charge de djaschenkir, [...], qu'il exerça jusqu'á la mort de Melik-Sâleh, et le massacre de son fils Melik-Moaddam. Sous le gouvernement de Schedjer-addorr, il fut nommé Atabek des armées." 34 (AL-MAQRIZI, $1837,2)$ Descrição similar é atribuída ao segundo sultão: "Il continua de monter en grade; [...]"35 (AL-MAQRIZI, 1837, 116).

\footnotetext{
34 "Ele subiu sucessivamente em níveis, colocado entre os emires Sâlehis, e obteu o cargo de djaschenkir, que ele exerceu até a morte de Melik-Sâleh, e o massacre de seu filho Melik-Moaddam. Todo o governo de Schedjer-addorr, ele foi nominado Atabek dos exércitos."

35 "Ele continuou a subir de níveis: [...]."
} 
NEARCD: Revista Eletrônica de Antiguidade 2020, Volume XII, Número I - ISSN 19882-8713

Núcleo de Estudas da Antiguidade -NEA

Universidade do Estada do Rio de Janeiro

ISSN 1982-8713

O autor considera crucial para o entendimento destas figuras o fato de terem ocupado cargos inferiores antes de tomarem o poder, utilizando em ambos os casos a ideia de uma escalada, de uma subida. É possível que estes termos relatem a longa duração do processo e a dificuldade enfrentada por estas figuras para a aquisição do poder. Lembramos que, como apontado anteriormente, muitos mamelucos não usufruíam da ascensão social, demonstrando uma trajetória incomum, mas não impossível. Esta "escalada social" também permitiria a compra de escravos e, então, a formação de um exército pessoal capaz de competir com outras figuras políticas.

Uma atenção especial é dada a Baybars, um sultão prestigiado em seu período e em tempos posteriores. O autor aponta que ele foi comprado por Al-Sâleh Ayyub, o último Aiúbida a governar o Egito. Após sua morte, o mameluco teria se aliado ao filho do governante antes deste ser morto pela elite opositora. Baybars, então, escala os cargos sob Moëzz e, após se alojar por um tempo na Síria, retorna ao Cairo e luta contra os tártaros sob o comando de Koutouz. A reputação conquistada durante seu reinado foi decisiva para mantê-lo no imaginário popular do período, a ponto de sua história ganhar espaço como um conto na compilação d'As Mil e Uma Noites.

Apesar de muitos sultões terem colocado seus filhos no trono após sua morte em uma tentativa de formar uma dinastia, na maioria das vezes estes filhos não se inseriam no grupo. Os filhos dos mamelucos, denominados de awlād al-nās, acabavam por ser absorvidos pela sociedade muçulmanas, visto que eram nascidos muçulmanos e terem o árabe como língua materna. Ulrich Haarman aponta que a precariedade do ensino de árabe durante o treinamento mameluco possibilitava a atuação dos filhos como mediadores ou tradutores entre os pais e a ulamā, por exemplo (HAARMAN, 1988, 88). Outra função comum era a ocupação de cargos altos de instituições religiosas ou intelectuais, que poderiam ser financiados pelos seus pais. A exclusão de futuras gerações, portanto, caracteriza a elite mameluca como uni-geracional, se limitando à primeira geração de origem escrava. O mantimento do grupo com uma identidade restrita se efetua com a constante compra de escravos turcos, criando uma rotatividade 
de indivíduos de mesma origem. Esta sistematização e perpetuação da escravidão militar continua pela duração de três séculos, visto que o mesmo acontecia com os mamelucos circassianos a partir de 1382.

Porém, o alistamento no exército não apresentava a mesma rigorosidade, principalmente com a aproximação das hordas mongóis e a marcante migração de populações. Por ser um dos pontos de referência geográfico e resistir às invasões, o Egito foi destino destes contingentes que incluíam príncipes, populações urbanas e mongóis foragidos. De acordo com Naokamachi Nobutaka, os exércitos mamelucos acabam por agregar estes indivíduos, porém sem a possibilidade concreta destes ascenderem a uma camada social superior (NOBUTAKA, 2006, 56-57).

\section{A Origem Turca}

A partir dos elementos principais que formavam a escravidão militar no Egito dos séculos XIII a XVI, percebe-se a construção de uma identidade baseada na experiência escrava, na adesão ao islamismo como religião e no mantimento da origem turca dos ex-escravos. A distinção da elite mameluca em relação à população egípcia não se deu apenas por seu porte militar e pelo poder político adquirido com a posse do trono, mas por sua diferenciação cultural e organizacional. Grande parte destes indivíduos passava por um processo comum de formação, possibilitando a identificação de um perfil geral que será explorado adiante.

Os escravos eram capturados de tribos turcas localizadas nas estepes euroasiáticas ainda jovens, por volta dos 10 anos de idade, e vendidos por mercadores em território muçulmano. Alguns fatores principais levavam à busca constante por abastecimento nestas regiões, como o fato de não serem muçulmanos e estarem próximos da fronteira do Islã, e a reputação adquirida pelos turcos de serem habilidosos na montaria e no uso de armas. A belicosidade vista nos turcos era considerada pelos muçulmanos como um talento de nascença. A falta de estabilidade e luxo atribuída às 
NEARCD: Revista Eletrônica de Antiguidade 2020, Volume XII, Número I - ISSN 19882-8713

Núcleo de Estudas da Antiguidade -NEA

Universidade do Estada do Rio de Janeiro

ISSN 1982-8713

tribos nômades contribuiu para o argumento de que os escravos seriam os mais aptos para a guerra se comparados aos governantes nativos muçulmanos.

Esta ideia é apresentada na obra de Ibn Khaldun, "Os Prolegômenos ou a Filosofia Social", e destaca que os escravos eram escolhidos por levarem vidas mais rudes e serem capazes de aguentar as fadigas da guerra. Diferente, portanto, dos governantes que viviam em meio à luxúria e ao ócio, conhecendo desde jovens a segurança e a prosperidade: “Certas vêzes acontece que, num império já atacado de debilidade que provém do ócio e dos hábitos de luxo, o soberano resolve tomar partidários e defensores entre povos alheios" (IBN KHALDUN, 1958, 302). A guerra, então, era atribuída como uma função pertinente a estes estrangeiros, determinando seu valor dentro da sociedade.

Khaldun reafirma esta prontidão ao combate e a relaciona com a importância da conversão destes grupos a escravos militares, como parte crucial do mantimento de um império:

No Oriente, aconteceu isso com o império dos Turcos (Mamluk), em que a maior parte do exército se compunha de dependentes e de clientes dos chefes. O sultão escolhe, entre os escravos que se importam para o país, um certo número de homens para fazer dêles cavaleiros e infantes. Estas novas tropas são mais valentes e mais experimentadas nas fadigas que as anteriores compostas dos filhos dos Mamluk, que se tinham educado no meio dos prazeres e do poder, sob a égide da soberania. (IBN KHALDUN, 1958, 302303)

A partir destas afirmações, o autor reforça o caráter uni-geracional do sultanato mameluco como um planejamento que garantiu seu sucesso. A imagem perpetuada tanto por Khaldun quanto por Maqrizi é de uma comunidade definida inicialmente por sua grande força militar. Ulrich Haarman afirma que o atrelamento imediato da função destes escravos à guerra poderia sufocar os interesses pessoais em relação às artes e aos estudos. Os mamelucos que eram bem-sucedidos nestas áreas eram tratados como raridades e exceções por muitos observadores externos. As áreas das ciências e da 
NEARCD: Revista Eletrônica de Antiguidade 2020, Volume XII, Número I - ISSN 19882-8713

Núcleo de Estudas da Antiguidade -NEA

Universidade do Estada do Rio de Janeiro

ISSN 1982-8713

cultura eram mantidas pela ulamā, que se mantinham em círculos fechados e igualmente excludentes.

Como mencionado anteriormente, o treinamento dos jovens comprados incluía o aprendizado sobre a religião e a língua árabe, e terminava por volta dos 18 anos de idade. A qualidade deste ensino, porém, não pode ser atestada. A principal forma de comunicação entre os soldados era ainda a língua turca, indicando que sua cultura se mantinha enraizada. Diversos relatos apontam sotaques na pronúncia árabe dos mamelucos e apresentam alguns indivíduos que mal falavam o árabe, dependendo de tradutores para a compreensão oral. Um caso abordado por Haarman foi de um concorrente a um alto cargo político que foi recusado, pois os avaliadores atestaram não conseguir diferenciar a pronúncia de lām e rā em sua fala. (HAARMAN, 1988, 84)

Ao compararmos a presença dos turcos no Islã antes do século XI com os apontamentos das fontes de Ibn Khaldun e Al-Maqrizi, percebe-se ainda que sua origem étnica se apresenta mais coesa e concreta em períodos posteriores. Como abordado, a presença turca nos exércitos se inicia muito antes dos mamelucos, porém é com a formação do Império Seljúcida que há uma mudança na composição étnica e a introdução de novos usos e mentalidade próprias. Claude Cahen afirma que antes:

Não se podia falar, portanto, de um povo turco - organizado como tal de acordo com suas próprias tradições - a não ser fora do âmbito do Islã. Pelo contrário, no século XI foi um conjunto de povos turcos que se estabeleceram em território muçulmano, modificando a sua composição etnográfica e introduzindo seus próprios costumes e mentalidade ${ }^{36}$ (CAHEN, 1972, 272).

É possível que por integrarem um conjunto de indivíduos de forma coesa, sua identidade comum os mantivesse inclusos e seguros na sociedade islâmica. Isto permitia

\footnotetext{
${ }^{36}$ No se podía hablar por entonces de un pueblo turco - organizado como tal según sus proprias tradiciones - más que fuera del ámbito del Islam. Por el contrario, em el siglo XI es un conjunto de pueblos turcos el que se establece em territorio musulmán, modificando su composición etnográfica e introduciendo unos usos y una mentalidad proprias
} 
NEARCD: Revista Eletrônica de Antiguidade 2020, Volume XII, Número I - ISSN 19882-8713

Núcleo de Estudas da Antiguidade -NEA

Universidade do Estada do Rio de Janeiro

ISSN 1982-8713

um certo de grau de liberdade quanto às tradições religiosas. Porém, o entendimento completo do árabe era considerado crucial para a compreensão dos textos religiosos que ditavam a lei, os costumes e o funcionamento do mundo muçulmano como um todo. Além disto, a língua árabe foi utilizada por Deus para se comunicar com Mohammad, que propagou seus ensinamentos também de forma oral. Além disto, a conversão religiosa tardia era alvo de diversas críticas feitas por religiosos como lbn Taymiyya, que apontavam uma ortodoxia duvidosa em meios aos mamelucos (HOURANI, 2006, 241).

Eram os impedimentos linguísticos que majoritariamente mantinham muitos turcos afastados das aspirações a cargos intelectuais, religiosos e jurídicos. Isto criava a oportunidade para que os $a w \mid \bar{d} d$ al-nās mediassem e traduzissem do turco para o árabe e vice-versa, visto que as duas línguas se faziam presentes desde seu nascimento. É comum que os filhos de mamelucos escolhessem cargos que demandavam o domínio completo do árabe, entre eles historiadores cujos trabalhos são conhecidos e estudados atualmente, como Ibn Taghribirdi, Ibn Haḍjar al-Asqalānī, al-Saknhāwī e o próprio al'Aynī.

Em “Os Prolegômenos, ou Filosofia Social, Ibn Khaldun dedica um dos capítulos para a questão da língua, intitulado "Ao indivíduo que, na sua mocidade adquiriu o hábito de falar uma língua não-árabe, a aquisição das ciências árabes é menos fácil que aos árabes natos". Nele, o historiador defende que uma língua só é completamente compreendida se esta é a primeira língua aprendida pelo indivíduo. O aprendizado posterior de outro idioma nunca será completo e tão bom entendimento quanto a primeira, independente da duração do aprendizado.

O estrangeiro, que possuísse, sòmente, um conhecimento imperfeito do árabe e do significado das palavras articuladas ou escritas pertencentes a esta língua, não poderia reconhecer, de maneira perfeita, as idéias que estas palavras representam, assim como se acabou de dizer; a não ser que o hábito de falar sua própria língua não tenha ficado como uma faculdade persistente, na época em que se desejava aplicar ao estudo do árabe. (IBN KHALDUN, 1958, 299) 
O uso do turco como principal meio de comunicação entre os mamelucos deixa claro que o árabe não se tornara um idioma facilmente entendido. 0 turco era expresso também nos nomes dos escravos e libertos, aspecto que não se repete nos filhos que recebiam nomes tradicionalmente árabes ou muçulmanos. Os awlād al-nās eram conscientemente distanciados da identidade dos pais desde seu nascimento.

É importante ressaltar que apesar de haver uma imagem e identidade comum, não havia consentimento interno em relações a interesses políticos. De fato, as relações entre os mamelucos eram tomadas por rivalidades internas, tanto no sultanato egípcio como fora. Uma interação entre o sultão de Roum e um grupo de emires e seus soldados mamelucos se destaca neste quesito. Ao receber uma carta acusatória de Moëzz em relação a um grupo de mamelucos emires que procuravam asilo em troca de serviços, 0 sultão indaga os emires recém-chegados a razão da sua indisposição com seu mestre. De acordo com Al-Maqrizi, o emir Alem-eddin-Sandjâr-Baschkirdi, após ouvir o nome do sultão do Egito, responde: "Si Melik-Moezz a dit dans sa lettre qu'il est notre maître, certes il s'est trompé. II n'était autre que notre collègue." 37 (AL-MAQRIZI, 1837, 54) A reação do emir deixa claro que a denominação de mameluco não é sinônimo de aliança interna.

Dois pontos se explicitam neste diálogo: a identidade comum que presentamos ao longo deste artigo, pautada na escravidão e na origem turca, é reconhecida e replicada no imaginário muçulmano; e os mamelucos não negam ou afastam esta imagem, porém, deixam claro que esta não significa aliança ou concordância. Mesmo geograficamente longe do Egito e oferecendo seus serviços a outro sultão, o emir foi questionado quanto à sua filiação aos mamelucos egípcios. A carta enviada por Moëzz também demonstra os atritos políticos presentes dentro da elite.

\footnotetext{
37 "Se Melik-Moëzz disse em sua carta que ele é nosso mestre, certamente ele se enganou. Ele não é mais que nosso colega."
} 
NEARCD: Revista Eletrônica de Antiguidade 2020, Volume XII, Número I - ISSN 19882-8713

Núcleo de Estudas da Antiguidade -NEA

Universidade do Estada do Rio de Janeiro

ISSN 1982-8713

A própria sucessão dos sultões era permeada pela disputa política, ditada por rivalidades entre as famílias mamelucas. O assassinato ou a prisão de concorrentes é presente durante todo o período do sultanato, afetando grande parte dos governantes. Isto levava a massacres, guerras internas e o deslocamento de tropas militares para outras regiões, como o resto da resposta do emir indica:

É nós que nos submetemos a sua autoridade, enquanto isto, nós tínhamos em nosso meio os homens mais velhos, de um nível muito destacado, muito belicoso, e muito digno do Império. Como recompensa, ele matou, emprisionou ou afogou parte de nós. Também, por escapar de sua fúria, nós tínhamos fugido e nos espalhamos por diferentes países. (AL-MAQRIZI, 1837, 54) ${ }^{38}$

É explicito na fala de Baschkirdi o governante do Egito não representa seus interesses ou dos que o acompanharam a Roum. Sua posição hierárquica não era reconhecida, mas a denominação de colega implica uma inicial atuação em conjunto e a equivalência de funções. Assim, entende-se da justificação do emir que o grupo identitário coeso de turcos mamelucos pode se desmantelar baseado em interesses próprios e na violência perpetuada pela competição interna.

\section{Considerações finais}

Ao partirmos de fontes externas ao objeto estudado, analisando as descrições e os valores atribuídos aos mamelucos, percebemos a construção de um imaginário comum nos documentos. As similaridades apontadas tanto pelos autores das fontes quanto pelos indícios e interações dos mamelucos relatados indicam que estes escravos e libertos militares constituem um setor próprio da sociedade islâmica, baseado na força militar de origem turca. Os relatos de acontecimentos singulares trazidos por Al-Maqrizi demonstram um perfil mais detalhado, apresentando nuances no comportamento ou

\footnotetext{
38 “'C'est nous qui lui avons déféré l'autorité, tandis que nous avions au milieu de nous des hommes plus âgés, d'un rang plus distingué, plus belliqueux, et plus digne de l'empire. Pour récompense, il a fait égorger, emprisonner, ou noyer une partie des nôtres. Aussi, pour échapper à sa fureur, nous avons prit la fuite, et nous sommes répandu dans différentes contrées."
} 
ISSN 1982-8713

na fala e a história por trás de cada personagem. Enquanto isso, Ibn Khaldun insere estes indivíduos em uma narrativa mais ampla com destaque para seu papel militar de forma unificadora.

Não podemos afirmar exatamente como os mamelucos reagiam pessoalmente a este imaginário, se realmente se identificavam com este ou não. Mas podemos afirmar que os privilégios fornecidos pela escravidão militar como uma instituição no Egito foram explorados. A identificação grupal permitiu a formação de uma espécie de solidariedade, uma união forte o suficiente para estabelecer seu próprio sultanato e a separação social em relação a outros escravos e muçulmanos para seu benefício. Além destes elementos, identificamos a cultura e as práticas turcas que possibilitaram um contato mais forte entre os indivíduos desta elite e dos exércitos.

\section{Referências Bibliográficas}

AL-MAQRIZI; QUATREMÈRE, Étienne Marc (trad.). Histoire des Sultans Mamlouks de I'Égypte. vol. 1. Paris: Oriental Translation Fund of Great Britain and Ireland, 1837-1845.

MITAI, Reuven. Military Slavery in The Islamic World: 1000 Years of a Social-Military Institution. Medieval Mediterranean Slavery, Universidade de Trier, p. 1-12, 2007. Disponível em: <http://med-slavery.uni-trier.de/publications/Amitai.pdf>. Acesso em: 27 de novembro de 2018.

AMITAI, Reuven. The Mamluk Institution, or One Thousand Years of Military Slavery in the Islamic World. In: DAVIS, David Brion. Arming Slaves: from classical times to the modern age. New Haven \& London: Yale University Press, 2006. p. 40-78.

BROADBRIDGE, Anne F. Academic Rivalry and the Patronage System in FifteenthCentury Egypt: al-'Aynī, al-Maqrīzī, and Ibn Ḥajar al-'Asqalānī. Mamluk Studies Review, v. 3, p. 85-107, 1999. Disponível em: <http://mamluk.uchicago.edu/MSR_III_1999Broadbridge.pdf>. Acesso em: 04 de maio de 2020.

CAHEN, Claude. El Islam: Desde los orígenes hasta el comienzo del Imperio otomano. Madrid: Ed. Castilla, 1972. 
HAARMAN, Ulrich. Arabic in Speech, Turkish in Lineage. Journal of Semitic Studies, v. 33, p. 81-114, 1988. Disponível em: <https://d-nb.info/112342943X/34>. Acesso em: 04 de maio de 2020.

HAMEL, Chouki El. "Raça", Escravidão e Islã no Marrocos: a questão dos Haratin. AfroÁsia, Salvador, 2004, n. 31, p. 09-18. Disponível em: <https://portalseer.ufba.br/index.php/afroasia/article/view/21070>. Acesso em: 04 de maio de 2020.

HOURANI, Albert. Uma História dos Povos Árabes. São Paulo: Companhia de Bolso, 2006.

IBN KHALDUN. Autobiografia de Ibn Khaldun. Os Prolegômenos, ou Filosofia Social. vol. 1. São Paulo: Safady, 1958-1960.

JAROUCHE, Mamede Mustafa. Uma Poética em Ruínas. In: Livro das Mil e Uma Noites. $3^{\circ}$ ed. Vol. 1. São Paulo: Globo, 2006.

NOBUTAKA, Nakamachi. The Rank and Status of Military Refugees in the Mamluk Army: a reconsideration of the Wafidiyah. Mamluk Studies Review, v. 10, n. 1, p. 55-81, 2006. Disponível em: <https://knowledge.uchicago.edu/record/1113>. Acessado em 04 de maio de 2020. 